\title{
A COMPARATIVE STUDY OF EFFICACY OF SILODOSIN AND TAMSULOSIN INPATIENT OF URETERIC CALCULI
}

\section{Surgery}

Dr. Sanjeev Kumar

M.S. (Gen. Surg.), Assistant Professor, Department of surgery, Madhubani Medical College and Hospital, Madhubani, Bihar.

Dr. Vishwa

Prakash Jha*

\section{Dr. N. K. Mishra}

M.S. (Gen. Surg.), Senior Resident, Department of surgery, Madhubani Medical College and Hospital, Madhubani, Bihar.*Corresponding Author

M.S. (Gen. Surg.), Professor and Head of Department, Department of surgery, Madhubani

Medical College and Hospital, Madhubani, Bihar.

Young Scientist (DST) Institute of Post-Graduate Medical Education and Research, A.J.C. Bose Road, Kolkata-700020, West Bengal, India.

\section{Dr. Debarshi Jana}

\section{ABSTRACT}

Objective: To compare the efficacy of Silodosin and Tamsulosin as a medical expulsive therapy, in the management of ureteric stone in the term of stone clearance and stone expulsion time.

Patients and method: A prospective randomized study was conducted on 60 patient aged $>15$ year who had unilateral or bilateral ureteic stone $<6$ $\mathrm{mm}$ or $6 \mathrm{~mm}$. patient were divided in two group. Group A receivedTamsulosin $(0.4 \mathrm{mg})$ and group B received Silodosin $(8 \mathrm{mg})$ daily for $28 \mathrm{days}$.the patient were followed up by ultrasonography, plain radiograph of kidney, ureter and bladder and IVU

Results:There is significantly higher stone clearance rate of $73 \%$ in Group A VS in group B of $90 \%$ (p value $<0.05$ ). Group B also showed a significant advantage for stone expulsion time. No severe complication were recorded during the treatment period. In Group A, out of 30 patient, 8 patient required ureteroscopic removal of stone or open ureterolithotomy but in groupB, only 3 patient required the same.

Conclusion: Our data show that silodosin is more effective than tamsulosin in the management of ureteric stone $<6 \mathrm{~mm}$ or $6 \mathrm{~mm}$ for stone clearance rate and stone expulsion rate.

\section{KEYWORDS}

\section{INTRODUCTION}

The urinary stone disease is one of the most common affection of modern society and has been described since antiquity with the westernization of global culture, affecting $13 \%$ of men and $7 \%$ of women . The life time risk of urinary stone disease is estimated to be between $5 \%$ and $12 \%$, in Europe and US, among all urinary stone, $20 \%$ present as uretric stone, of which $70 \%$ found in lower third of ureter To date, minimally invasive therapy, such as extracorporeal shock wave lithotripsy and ureterolithotripsy, represent efficacious treatment modalities in almost all case. Nevertheless, these procedureimply high cost and not risk free $\mathrm{f}^{3}$. A watchful waiting approach has been reported to be associated with spontaneous stone expulsion in up to $50 \%$ of the case, but some complication may occur such as urinary tract infection ${ }^{4}$ There has been a paradigm shift in the management of ureteric calculi in the past decades, with the introduction of lesser invasive method and newer drugs. The alpha -1 blocker which were first developed as an anti hypertensive drug, now being effectively use in the treatment of benign prostatic hyperplasia, due to their relaxing property on urinary tract. Recent studies have reported excellent results with medical expulsion therapy for distal ureteric calculi, with alpha 1 blocker. Both American urological association (AUA) and European association of urology(EAU) also recommended alpha 1 blocker for the treatment of ureteric stone.Their use in the treatment of distel ureteric stone arose from the consent that they could induce a selective relaxation of ureteral smooth muscles, which could inhibit the urethral spasm and results in dialation of ureteral lumen.

In 1970,Malin et al demonstrated the presence of alpha and beta adrenergic receptor (AR) in the human ureter ${ }^{5}$. Alpha 1 are the most abundant subtype at the level of ureteric smooth muscles ${ }^{6}$. Itoh et al alpha 1a, alpha 1B, alpha 1D). Antagonist of these receptor have been prove to decrease ureteric basal tone, peristalsis activity and contraction thus decreasing intraureteric pressure and increasing urine transport . these meta-analysis have confirmed a positive effect of alpha blocker therapy on stone expulsion rate ${ }^{7}$. Alpha blocker has been proved to improve the likelihood of spontaneous stone passage and to decrease both the time to stone passage and analgesic requirement ${ }^{8}$.

According to European Association of urology Guideline, alpha blocker are recommended for Medical expulsion therapy ${ }^{9}$. Patient who elect for MET should have well controlled pain , no clinical evidence of sepsis and adequate renal function reserve ${ }^{10}$.
The alpha 1A/D selective alpha blocker TAMSULOSIN has been demonstrated to be safe and effective drug that enhance spontaneous passage of distal ureteric stone seized $10 \mathrm{~mm}$ or smaller $^{11}$. recen studies havedemonstrated that the Alpha 1A subtype plays the major role in mediating phenyephrine induced contraction in the human isolated ureter .Kobayashi et al found that the selective alpha 1A adrenergic receptor antagonist, SILODOSIN was more effective than the selective alpha 1D adrenergic receptor antagonist, BMY-7378, for noradrenaline induced contraction in the human ureter ${ }^{12}$. According to Tsuzaka et al, silodosin was clinically superior for stone expulsion when compare to tamsulosin ${ }^{13}$

Hence, a study was planned to see the efficacy of SILODOSIN (8mg/day) - a new alpha 1a antagonist with TAMSULOSIN $(0.4 \mathrm{mg} /$ day $)$-alpha $1 \mathrm{~A} / 1 \mathrm{D}$ antagonist.

\section{MATERIALS AND METHODS}

In $\mathrm{MMCH}$, All cases of flank pain or lower abdominal pain with urinary symptoms were admitted either in emergency or OPD. After proper investigation, 60 patients having ureteric calculi without hydronephrotic changes or any congenital anomaly or any evidence of infection were selected in study.

This prospective study was conducted during the period of August 2019 to July 2020 in Department of Surgery, Madhubani Medical College \& hospital, Madhubani, Bihar.

Each patient was examined thoroughly after taking detailed history. The diagnosis and examination was made with history, clinical features and $\mathrm{CBC}, \mathrm{B} /$ Urea, $\mathrm{S}$ / Creatinine, Routine urine, digital XRAY KUB, IVU, USG of whole abdomen to support the diagnosis.

- The patients evaluated withureteic stones were managed conservatively. Every patient provided consent after receiving information about nature of study, time of study end , adverse effect, and the possibility of intervention if needed.

The patients confirmed with stone in ureter were divided in two groups by random selection. The patients were divided into two groups as follows :

- Group A: Patients with ureteral calculi received single dose of Tamsuliosin $(0.4 \mathrm{mg} /$ day $)$ 
- GroupB : patient with ureteric calculi received single dose of Silodosin ( $8 \mathrm{mg} /$ day).

Both the group were strictly instructed to drink minimum of 2 litre of water daily and to use symptomatic treatment with tab diclofenac on demand. All the patients were advised to filter/strain their urine stream to detect stone passage or collect the urine in transparent container and to stop medication when the stone was expulsed and report for confirmation.

The duration of trial was until expulsion of the stone, but no longer than 4weeks.

The patients was then observed weekly and asked for any history of passage of calculi and digital X-RAY KUB \&ultrasound scan was repeated after 15 days to look for any passage of calculi.

The findings were recorded and the patients were monitored and followed up for a period of one month. The passage of stones, was confirmed with ultrasonography \& digital X-RAY KUB.

After 1 month if treatment failed, conservative management was discontinued and patient was advised for surgical intervention in higher centre where facilities for URS and ESWL is available.

\section{INCLUSION CRITERIA}

(a) Patients with age $>15$ years

(b) Calculus in the ureter with stone size $6 \mathrm{~mm}$ or less

(c) Stones at multiple sites were also included.

\section{EXCLUSION CRITERIA:}

- Stone larger than $6 \mathrm{~mm}$

- Patient who undergone same treatment before

- Clinical and laboratory signs of urinary tract infections (UTIs)

- Severe hydronephrosis on ultrasound examination (gross pelvicalycealdilatation with parenchymal thinning).

- Co-morbid conditions such as diabetes, alteration in renal parameters (serum creatinine $>1.5 \mathrm{mg} / \mathrm{dl}$ ).

- Previous history or ureteral manipulation and/or surgery.

- Pregnancy.

- Urethral stricture

- Patient on alpha / beta blocker or CCB or steroid.

- Patient who are hypersensitive to temsulosin or silodosin

In each case studied, an elaborate history and physical examination and relevant investigations were carried out as depicted in proforma.

The treatment of the cases consisted of Alpha blocker drug tamsulosin $(0.4 \mathrm{mg} /$ daily $)$ and silodosin $8 \mathrm{mg} /$ day given orally for 30 patients in each group along with NSAIDs, prednisolone in tapering dose and plenty of oral fluids.Patients who failed to expel the calculus with the above treatment were sent to Departmentof Urology for ureteroscopic removal of stone.

The patients were followed up for one month.

\section{RESULT:}

Data were collected and compared in term ofpatients demographics, socio economic status, stone status, stone size and site of stone, stone expulsion rate and incidence of side effect.

The stone clearance rate was significantly different between the group, at $73 \%$ in group $\mathrm{A}$ and $90 \%$ in group $\mathrm{B}(\mathrm{p}=0.05)$. In group $\mathrm{B}$,stone expulsion time was also significantly shorter than group B at mean of 19.1 days as compared to GroupA with mean of 22.9 days.

Treatment outcome parameters in these Group

\begin{tabular}{|c|c|c|c|}
\hline & Tamsulosin(A) & Silodosin(B) & P value \\
\hline Expulsion rate & $73 \%(23)$ & $90 \%(27)$ & $<0.05$ \\
\hline Stone expulsion time & 22.9 & 19.1 & $<0.05$ \\
( mean) Failure rate & $27 \%$ & $10 \%$ & $<0.05$ \\
\hline
\end{tabular}

Demograraphic characteristics of these group .

\begin{tabular}{|c|c|c|}
\hline Characteristic & $\begin{array}{c}\text { GroupA } \\
\text { (tamsulosin ) }\end{array}$ & $\begin{array}{c}\text { GroupB } \\
\text { (silodosin) }\end{array}$ \\
\hline Mean Age( in year) & 32.6 & 29.6 \\
\hline Sex( male/female) & $17 / 13$ & $18 / 12$ \\
\hline Laterality( right/ left) & $19 / 11$ & $13 / 17$ \\
\hline Location( upper/ middle/ lower) & $3 / 10 / 17$ & $6 / 6 / 18$ \\
\hline Mean Stone size (in mm) & $5.7(1.2)$ & $5.3(1.6)$ \\
\hline
\end{tabular}

In our study, In the group A, $3 \%$ of patients passed the ureteric calculus within 7 days, $6.7 \%$ of the patients passed the calculus within 14 days, $30 \%$ of the patients passed the calculus within 21 days and $33.3 \%$ of the patients passed the calculus within 28 days of follow up with mean expulsion time is 22.9 days. $26.6 \%$ patients did not pass the calculus. Pvalue is less than 0.05 , hence statistically significant.

In group B , $13 \%$ of patient passed stone within 1 st week , $23 \%$ passed stone with in $2^{\text {nd }}$ week, $26.6 \%$ of patient passed stone in $3^{\text {rd }}$ week and same $26.6 \%$ of patient passed stone within $4^{\text {th }}$ week with mean expulsion time is 19.1 days. $10 \%$ patient did not pass the calculus. $\mathrm{P}$ value is less than 0.05 , hence statistically significant.

Time of expulsion of stone in both the GROUP

\begin{tabular}{|c|c|c|}
\hline $\begin{array}{c}\text { Time of expulsion in } \\
\text { week }\end{array}$ & $\begin{array}{c}\text { Group A } \\
\text { (Tamsulosin) }\end{array}$ & $\begin{array}{c}\text { GroupB } \\
\text { (Silodosin) }\end{array}$ \\
\hline $1^{\text {st }}$ week & 1 & 4 \\
\hline $2^{\text {nd }}$ week & 2 & 7 \\
\hline $3^{\text {rd }}$ week & 9 & 8 \\
\hline $4^{\text {th }}$ week & 10 & 8 \\
\hline Failure (in number) & 8 & 3 \\
\hline Failure\% & 26.6 & 10 \\
\hline Mean expulsion time & 22.9 days(5.6) & 19.1 days(7.2) \\
\hline
\end{tabular}

In Group A, $6.7 \%$ ( 2 patient) of the patient had orthostatic hypotension which was the most common side effect of this group .only one patient had dizziness, retrograde ejaculation, dizziness, nasal congestion and headache.

But in group B, $10 \%$ (3 patients) of the patient had retrograde ejaculation which was the most common side effect of this group. Two patient developed mild nasal congestion and only one patient had mild headache. None of the patient of group B developed orthostatic hypotension and dizziness.

\begin{tabular}{|c|c|c|}
\hline Side effect & Group A & Group B \\
\hline Orthostatic hypotension & 2 & 0 \\
\hline Retrograde ejaculation & 1 & 3 \\
\hline Dizziness & 1 & 0 \\
\hline Nasal congestion & 1 & 2 \\
\hline Headache & 1 & 1 \\
\hline
\end{tabular}

\section{DISCUSSION:}

Ureteroscopy and SWL remains the most effective treatment for ureteric stone, however, they are expensive and not risk free. Spontaneous stone expulsion can occur in up to $50 \%$ of cases. Nevertheless, these complication as ureteric colic, UTI, hydronephrosis may occur. Recently, the use of various adjuvant medication as MET for ureteric stone help to reduce pain, complication, and increase the rate of stone clearance ${ }^{(12,13)}$.

The alpha 1A and alpha 1D adrenoreceptor are the most abundant subtype in distal ureter, stimulation of these a1 adrenoreceptor leads to increase in both the frequency of ureteric peristalsis and force of contraction. However, blockade of these receptor decrease basal ureteric tone, decrease peristalsis frequency and amplitude leding to decrease in intraluminal pressure while the rate of urine transport increase and thus increasing chance of stone passage ${ }^{14}$.

Highly selective alpha1a adrenoreceptor blockers have been developed to minimize the cardiovascular adverse effect while maintaining the efficacy on urinary tract ${ }^{15}$. Tamsulosin is selective alpha 1 blocker with 10 fold greater affinity for alpha $1 \mathrm{~A}$ and alpha $1 \mathrm{D}$ adrenoreceptor subtype than the alpha 1B subtype, while the affinity of Silodosin for Alpha 1A subtype is about 162 and 50 fold greater than its affinity for the alpha alpha 1B and alpha 1D adrenoreceptoer subtype respectively, which explain weak cardiovascular adverse effect of Silodosin.

In our present study, the stone clearance rate was significantly higher in silodosin group (90\%) compared with the tamsulosin group $(73 \%)$ with $\mathrm{p}<0.05$. Mean stone expulsion time insilodosin group is significantly low (19.1 days) as compare to tamsulosin( 22.9 days ). Study done by Gupta et $\mathrm{al}^{16}$ who reported stone clearance rate of $82 \%$ and $64 \%$ for silodosin and tamsulosin respectively with stone expulsion time in the silodosin and tamsulosin , at 12.5(3.5) vs 19.5 (7.5) days respectively.However, Imperatoreet $\mathrm{al}^{17}$ reported a nonsignificant difference of stone clearance rate between silodosin $(88 \%)$ and temsulosin $(84 \%)$. 
For safety issue and adverse effect, both drug are safe and well tolerated and the most frequently encountered side effect in Silodosin group was retrograde ejaculation which is reported in $10 \%$ and $3 \%$ in tamsulosin group (A). Postural hypotension is most common in tamsulosin group (6.7)\% which was managed conservatively . No patient discontinued treatment because of retrograde ejaculation and postural hypotension as both were reversible.

\section{CONCLUSION:}

Tamsulosin and silodosin are safe and effective treatment that enhance spontaneous passage of stone sizes $6 \mathrm{~mm}$ or smaller. Silodosin are more effective than tamsulosin in term of stone expulsion rate $90 \%$ and $73 \%$ respectively ( $\mathrm{p}$ value $<0.05$ ) as well time taken for the stone expulsion $19.1 \pm 5.6$ days and $22.9 \pm 7.2$ days respectively ( $\mathrm{p}$ value $<0.05$ ). Our study also demonstrate lower incidence of orthostatic hypotension $(0 \%)$ in case of silodosin but slight higher incidence of abnormal ejaculation (10\%) as compared to tamsulosin(3.3\%).

\section{REFERENCES}

1. Hollingsworth JM Rogers MA, Kaufman SR et al, medical therapy to facilitate urinary stone : a meta anylysis, Lancet 2006,368(9542);1171-19.

wolf JS treatment selection and outcome : ureteral calculi, urolclinNorth Am wolf JS , treatment

3. Dellabella M, Milanese G, Muzzonigro G. Randomized trial of theefficacy of tamsulosin, nifedipine and phloroglucinol in medicalexpulsivetherapy for distal uretera calculi. JUrol. 2005; 174:167-72.

4. Borghi L, Meschi T, AmatF, et al .Nifidipineand methylprednisolone in facilitating urethral stone passage : a randomised, double blind, placebo-controlled study . J Uro 1994:152(4): 1095-8

5. Malin JM Jr, Deane RF, Boyarsky S. Characterisation of adrenergicreceptors in human ureter.Br J Urol. 1970; 42:171-4

6. Itoh Y, Kojima Y, Yasui T, et al. Examination of alpha 1 adrenoceptorsubtypes in the human ureter. Int J Urol. 2007; 14:749-53.

7. De Sio M, Autorino R, Di Lorenzo G, et al. Medical expulsivetreatment of distal-ureteral De Sio M, Autorino R, Di Lorenzo G, et al. Medical expulsivetreatment of distal-

8. Watts HF, Tekwani KL, Chan CW, et al. The effect of alpha blockade in emergency patient with ureterolithiasis. J emerg med 2010,38:368-73

9. Hollingsworth JM, Rogers MA, Kaufman SR, et al, HollenbeckMedical therapy to facilitate urinary stone passage: a meta-analysis..Lancet. 2006;368:1171-9.

10. Türk C, Knoll T, Petrik A, et al. Guidelines on UrolithiasisEuropean Association of Urology Updated March 2011

11. Kobayashi S, Tomiyama Y, Hoyano Y, et al. Gene expressionsmechanical functions of 1-adrenoceptor subtypes inmouseureter. World J Urol. 2009; 27:775-80.

12. Tsuzaka Y, Matsushima H, Kaneko T, et al. Naftopidilvssilodosinin medical expulsive therapy for ureteral stones: a randomized controlledstudy in Japanese male patients. Int J therapy for ureteral st

13. Dellabella M, Milanese G, Muzzonigro G. Randomized trial ofthe efficacy of tamsulosin, nifedipine and phloroglucinol inmedical expulsive therapy for dista ureteral calculi. J Urol2005;174:167-72.

14. Griwan MS, Singh SK, Paul H, Pawar DS, Verma M. Theefficacy of tamsulosin in lowe ureteral calculi. Urol Ann2010;2-63-06.

15. Rossi M, Roumegue're T. Silodosin in the treatment of benignprostatic hyperplasia Drug Des DevTher2010;27(4):291-7.

16. Kumar S, Jayant K, Agrawal MM, Singh SK, Agrwal S, ParmarKM. Role of tamsulosin, tadalafil, and silodosin as the medicalexpulsive therapy in lower ureteric stone: a randomized trial (apilot study). Urology 2015;85:59-63.

17. Imperatore V, Fusco F, Creta M, Di Meo S, Buonopane R,Longo N, et al. Medical expulsive therapy for distal uretericstones: tamsulosin versus silodosin. Arch expulsive therapy for distal
ItalUrolAndrol $2014 ; 86 ; 103-07$ 